\title{
Significance of Discriminant Analysis in Prediction of Pregnancy in IVF Treatment
}

\author{
Anna Justyna Milewska ${ }^{1}$, Dorota Jankowska ${ }^{1}$, Urszula Cwalina ${ }^{1}$, \\ Dorota Citko $^{1}$, Teresa Więsak ${ }^{2}$, Brian Acacio ${ }^{3}$, Robert Milewski ${ }^{1}$ \\ 1 Deartment of Statistics and Medical Informatics, Medical University of Bialystok, \\ Poland \\ 2 Department of Gamete and Embryo Biology, Institute of Animal Reproduction and \\ Food Research of Polish Academy of Sciences, Olsztyn, Poland \\ 3 Acacio Fertility Center, Laguna Niguel, California, USA
}

\begin{abstract}
Many factors play an important role in prediction of infertility treatment outcome (for example, female age and quality of oocytes or embryos are the most important prognostic factors concerning positive IVF outcome). The purpose of this study was to identify a set of variables that could fulfill criteria for prediction of pregnancy in IVF patients through the application of data mining - using the discriminant analysis method. The principle of this method is to establish a set of rules that allows one to place multi-dimensional objects into one of two analyzed groups (pregnant or not pregnant). Six hundred and ten IVF cycles were included in the analysis and the following variables were taken into consideration: female age, number and quality of retrieved oocytes, number and quality of embryos, number of transferred embryos, and outcome of treatment. Discriminant analysis allowed for the creation of a model with a $51.22 \%$ correctness of prediction to achieve pregnancy during IVF treatment and with $74.07 \%$ correctly predicted failure of pregnancy. Therefore, the created model is more suitable for the prediction of a negative outcome (lack of pregnancy) during IVF treatment and offers an option for adjustments to be made during infertility treatment.
\end{abstract}

\section{Introduction}

The main purpose of medical science is to determine the cause of disease, predict the results of treatment and describe biological processes. It is very often difficult to establish reason-reaction relationships. Such is the case with the problem patients experience with becoming pregnant during infertility treatment. The success rate for pregnancy in IVF patients is approximately $40 \%$ per embryo transfer (Milewski et al., 2013a). This could be improved 
if it were possible to predict results of different treatments or modifications of the treatment.

The most important previously established prognostic factors of positive IVF outcomes are female age and quality of oocytes or embryos. In the process of IVF, the retrieved oocytes are evaluated as follows: mature MII (the presence of the first polar body and the degree of dispersion of cumulus cells that surrounds the oocyte), immature MI (oocytes without a visible polar body), and immature GV (with a visible germinal vesicle and tight corona radiate and low degree dispersion of cumulus cells) (Radwan et al., 2011; Veeck, 1998). The correctly fertilized oocyte should display two pronuclei and two polar bodies. Some embryologists take into consideration the granularity of cytoplasm or size and position of the pronuclei within the oocyte or number and alignment of nucleoli within the pronuclear structure. After insemination (ICSI - intracytoplasmic sperm injection or conventional insemination), the developing embryo is assessed periodically before its transfer to the uterus; the number and symmetry of blastomeres, degree of cytoplasmic fragments and quality of cytoplasm, and quality of inner mass and trophectoderm in blastocysts are assessed (Radwan et al., 2011). Such an amount of information is difficult to embrace by either the clinician or anyone else. So far, statistical analyses have been focused on selection of only one predictor, without satisfactory results. However, taking a group of variables into consideration provides an opportunity for improving efficacy of prediction. Therefore, statistical models of differing levels of complexity that can handle multiple-size databases, such as data mining methods, are very useful (Milewski et al., 2011). The most popular data mining methods are: the artificial neuron network (Milewski et al., 2009, 2013b), principal component analysis (Milewska et al., 2014), cluster analysis (Milewska et al., 2013), basket analysis (Milewska et al., 2011) and correspondence analysis (Milewska et al., 2012).

The objective of our study was to apply discriminant analysis to identify a set of variables that allow for prediction of positive (pregnancy) or negative (lack of pregnancy) IVF outcome.

\section{Discriminant Analysis}

Discriminant Analysis is a classification method. Its purpose is to develop rules for assigning multidimensional objects to one of a number of considered groups (Stanisz, 2007). This data mining technique belongs to a group of supervised learning tasks. The method requires extracting a train- 
ing dataset from an analyzed database. Using this training dataset, the algorithm can learn which values of characteristics may determine placement into various classes. The remaining validation database can be used to estimate the quality of the classifier.

The most important assumptions of the method are:

- normal distribution of the variables included in the model in each analyzed group,

- homogeneity of the variance-covariance matrix in the groups,

- lack of correlation between the initial variables to avoid duplication of information.

Moreover, this method is sensitive to the outliers.

An important aspect of discriminant analysis is use of a canonical discriminant function. This function determines the direction of projection data to obtain the highest possible degree of separation between the analyzed groups. The potential subsequent discriminant functions also fulfill the above condition and are orthogonal to the previously established. The number of discriminant functions is at most equal to the number of variables taken into consideration during classification $(k)$ and no more than the number of groups $(g)$ minus one. Usually the discriminant function takes the linear form:

$$
Y=\beta_{0}+\beta_{1} X_{1}+\beta_{2} X_{2}+\cdots+\beta_{k} X_{k}
$$

$k-$ number of variables taken into consideration during classification e.g. discriminant variables

$X_{i}$ - discriminant variables (explanatory variables), $i=1,2, \ldots, k$

$\beta_{i}-$ coefficients of discriminant function, $i=1,2, \ldots, k$

$w-$ maximum number of discriminant functions; $w=\min \{k, g-1\}$

$Y=\left[\begin{array}{c}Y_{1} \\ Y_{2} \\ \vdots \\ Y_{w}\end{array}\right]-$ canonical discriminant functions

It is created by maximizing the quotient of between-class variability divided by within-class variability. Coefficients $\beta_{1}, \beta_{2}, \ldots, \beta_{k}$ of these functions are determined from the equation:

$$
(M-\lambda W) \beta=0
$$

$M$ - between-group sums of squares and cross products matrix

$W$ - within-group sums of squares and cross products matrix 
It allows one to determine eigenvalues $\lambda_{1}>\lambda_{2}>\ldots>\lambda_{w}$, with corresponding eigenvectors $\beta=\left(\beta_{1}, \beta_{2}, \ldots, \beta_{k}\right)$.

To determine how many discriminant functions should be considered as significant, the test statistic based on Wilks's lambda $(\Lambda)$ is used:

$$
\begin{gathered}
\chi^{2}=-\left(n-\frac{k+g}{2}-1\right) \ln \Lambda_{j} \\
\Lambda_{j}=\prod_{i=j+1}^{w} \frac{1}{1+\lambda_{i}}=\frac{\operatorname{det}(W)}{\operatorname{det}(W+M)}
\end{gathered}
$$

$n$ - number of analyzed observations

This presents the possibility of verifying the hypothesis that more than $\mathrm{j}$ functions have insignificant input into classification. This test statistic has chi-square distribution with a $(k-j)(g-j-1)$ degree of freedom. Wilks's lambda takes values in the range of $(0,1)$ and the lower the value, the better the discriminant power is. This is due to the form of the function. Its value can be assessed with the formula:

$$
\frac{\lambda_{i}}{\sum_{i=1}^{w} \lambda_{i}}
$$

This value gives information about the percentage of between-group variation, which is explained by $i$-th of the discriminant functions.

The relevance of taking the $i$-th variable in the discriminant function into consideration can be confirmed by the $F$ statistic (Dobosz, 2001):

$$
\begin{gathered}
F_{i}=\left(\frac{n-g-k+1}{g-1}\right) \frac{1-\Lambda_{+}}{\Lambda_{+}} \\
\Lambda_{+}=\frac{\Lambda_{j}}{\Lambda_{j}^{(i)}}
\end{gathered}
$$

$\Lambda_{j}^{(i)}-$ partial Wilks's lambda; Wilks's lambda determined after removing $i$ variable from the model

$\Lambda_{j} \quad$ - Wilks's lambda determined for the model with inclusion of the $i$ variable.

F statistics has F-Fisher distribution with a $(g-1)$ and $(n-g-k+1)$ degree of freedom. It permits one to establish whether a specific variable has a significant input into the discriminant function. Moreover, it can indicate which characteristics best differentiate studied classes. 
Discriminant analysis allows one to work out rules for classification of cases into the known groups. There are several ways this can be achieved. One way is to determine classification functions. The number of functions is equal to the number of groups and they take the form (Stanisz, 2007):

$$
K_{i}=c_{i 0}+c_{i 1} X_{1}+c_{i 2} X_{2}+\cdots+c_{i k} X_{k}
$$

$K_{i}$ - classification functions, $i=1,2, \ldots, g$

$c_{i j}$ - coefficients of classification functions (weights); $i=1,2, \ldots, g ; j=$ $0,1, \ldots, k$

$X_{j}$ - discriminant variables taken into consideration in the discriminant functions, $j=1, \ldots, k$

In this case, the object is included into the $i$ group for which the $K_{i}$ value is the highest. Classification can also be performed based on the Mahalanobis distance of the observation $(X)$ from the centroids of the groups (Dobosz, 2001):

$$
D\left(X, G_{j}\right)=\sqrt{\left(X-\bar{X}_{j}\right) S_{j}^{-1}\left(X-\bar{X}_{j}\right)^{T}}
$$

$X \quad$ - analyzed observation

$\bar{X}_{j}-$ centroid of $j$-th group, $j=1,2, \ldots, g$

$S_{j}^{-1}$ - inverse of within-group covariance matrix of $\mathrm{j}$-th group, $j=$ $1,2, \ldots, g$

The centroid of the group is the point at which the mean values of discriminant variables in the group are the coordinates. The analyzed case is included into that group where the centroid is the closest.

The quality of such a classifier is assessed by calculating the percentage of correctly classified cases in the validation dataset. Percentages of both the correctly assigned observations in each group and in the whole dataset should be determined. Classification using the discriminant analysis method is useful if such percentage is higher than the percentage of correctly assigned objects obtained in a random classification.

The quality of prediction can be improved by taking into consideration a priori probabilities of placing the objects into classes during the development of discriminant functions and classification functions (Stanisz, 2007). They can be determined according to the proportion of cases in each group in the training dataset. They can also be defined based on knowledge of the studied phenomenon or can be established as the same for all groups. The inclusion of a priori probabilities is really important because it can help reduce the cost of misclassification. 


\section{Application of Discriminant Analysis in Medical Science}

In medical research, the affiliation of a set of variables to one or several groups is often analyzed. For example, a set of variables describing the state of the patient's health and the patient's history is analyzed in order to classify patients into the following groups: good or poor prognosis, complete or partial cure, or lack of reaction to the treatment.

There are already numbers of papers describing the application of discriminant analysis in such disciplines as veterinary science (De Clercq et al., 2015; Fanos et al., 2014), plant science (De Leon et al., 2015) and neuroscience (Vilke et al., 2014). In medicine, discriminant analysis has been employed in many areas.

In the literature, there are some examples of the use of discriminant analysis in anatomy (Alunni et al., 2015; Lee et al., 2015). In the article by Alunni et al. (2015), the authors show how to use the femoral bones to determine gender. In the second cited article by Lee et al. (2015), information is presented regarding how volume and surface area of different bone types were used to the same aim.

Discriminant analysis is also used in oncology. This method was used to find a set of variables that might differentiate normal skin from skin with cutaneous melanoma, offering a possibility for detection of skin melanoma (Pires et al., 2014). Discriminant analysis can be useful in other branches of oncology as well, for example in gynecological oncology. Wouter Wegdam et al. (2012) analyzed patients with ovarian masses and applied a selected classifier to distinguish cancer from benign tumors. Similarly, Seung Cheol Kim et al. (2014) were able to discriminate between patients with ovarian cancer and healthy individuals.

General medicine and pediatrics are branches of medicine where discriminant analysis is also being applied. To give a few examples, Zhanlian Huang et al. (2015) have looked for the variables useful in diagnosis of liver fibrosis in hepatitis B patients. Noriaki Maeda et al. (2015) have attempted to determine characteristics that predict fall status in stroke patients. The Philippa Prentice et al. (2015) used discriminant analysis out of several other methods to compare lipidomic profiles between breast-feeding, formula-feeding, and mixed-feeding infants.

Discriminant analysis is also used for data from the field of gynecology. Pappas et al. (2015), for example, showed the influence of genetic factors and the intra-uterine environment on the incidence of neurocognitive impairment in premature infants. Another example of a paper describing the application of discriminant analysis in this area is one published in 2014 
by Gajjar et al. Therein, the authors presented an alternative for classic cervical cytology. Some articles also refer to IVF procedures. The application of discriminant analysis and principal component analysis (PCA) led to the identification of metabolites that can be useful in differentiating between patients who are able to get pregnant and those who will fail the IVF procedure (Xia et al., 2014). On the other hand, Singh Neeta et al. (2013) compare accuracy of different variables to predict ovarian response and Gnoth et al. (2008) to predict ovarian reserve and pregnancy rate. Discriminant analysis can also be used to assess the predictive ability of different endometrial parameters for achieving pregnancy (Zhao et al., 2014).

\section{Application of Discriminant Analysis in Infertility Treatment}

Statistica Data Miner + QC 12.5 software (StatSoft) was used to analyze the data presented herein. The Mann-Whitney U test was applied to determine differences between the groups. To determine the power of predictors, the discriminant analysis and the ROC analysis with area under curve (AUC) were used. The data of 610 IVF cycles from a fertility center in the USA with the following variables were used: female age, number of follicles before retrieval, number and maturity of retrieved oocytes (GV, MI, MII, MII*), number and quality of embryos (2PN, NEF 2PB, non2PN, cleavage on day $3, \geq 7$ cells on day 3 , number blastocysts on day 5 and day 6 ), number of transferred embryos, and number of pregnancies (Table 1). All cycles were ICSI cycles. In addition, new variables were created: classes of retrieved oocytes in percentages (denominator was the total number of retrieved oocytes) and percentage of embryos in eight developmental stages of observation (denominator was the total number of fertilized oocytes). The variables that significantly differentiated the two groups - pregnant from not pregnant - were: female age, number of follicles, number of retrieved oocytes, MII after ER (\%), MII at ICSI (\%), number of fertilized (ICSI) oocytes, $2 \mathrm{PN}(\%), \mathrm{NEF} 2 \mathrm{~PB}(\%), \geq 7$ cells on day $3(\%)$, blasts on day $5(\%)$ and $6(\%)$.

The data were randomly assigned to two groups - a training set $(n=515)$ and a validation set $(n=95)$ - before the analysis. To search for the discriminant variables that best identify differences between data of pregnant and non-pregnant patients (pregnancy was the dependent variable), the training group was used. The discriminant function was based on the following five variables: blasts on day $5(\%)$, female age, number of transferred embryos, $\geq 7$ cells on day $3(\%)$, and NEF $2 \mathrm{~PB}(\%)$ and was 
Anna Justyna Milewska et al.

Table 1. Patients' characteristics (training and validation groups)

\begin{tabular}{|c|c|c|c|c|}
\hline $\begin{array}{l}\text { Variables } \\
\text { median }(\bar{x}) \\
\min -\max \end{array}$ & $\begin{array}{l}\text { All patients } \\
(n=610)\end{array}$ & $\begin{array}{c}\text { Pregnant } \\
(n=273,44.75 \%)\end{array}$ & $\begin{array}{c}\text { Non-pregnant } \\
(n=337,55.25 \%)\end{array}$ & P-value \\
\hline $\begin{array}{l}\text { Female age } \\
\text { (years) }\end{array}$ & $\begin{array}{l}38.00(37.50) \\
23.00-48.00\end{array}$ & $\begin{array}{l}36.00(36.03) \\
24.00-46.00\end{array}$ & $\begin{array}{l}40.00(38.68) \\
23.00-48.00\end{array}$ & $<0.001$ \\
\hline $\begin{array}{l}\text { Follicles } \\
\text { (n) }\end{array}$ & $\begin{array}{l}13.00(13.60) \\
1.00-45.00\end{array}$ & $\begin{array}{l}14.00(15.47) \\
2.00-40.00\end{array}$ & $\begin{array}{l}11.00(12.08) \\
1.00-45.00\end{array}$ & $<0.001$ \\
\hline $\begin{array}{l}\text { Retrieved oocytes } \\
\text { (n) }\end{array}$ & $\begin{array}{l}10.00(12.70) \\
1.00-65.00\end{array}$ & $\begin{array}{l}12.00(14.90) \\
1.00-54.00\end{array}$ & $\begin{array}{l}8.00(10.92) \\
1.00-65.00\end{array}$ & $<0.001$ \\
\hline $\begin{array}{l}\text { MII after ER } \\
(\%)\end{array}$ & $\begin{array}{l}0.70(0.67) \\
0.00-1.00\end{array}$ & $\begin{array}{l}0.70(0.73) \\
0.00-1.00\end{array}$ & $\begin{array}{l}0.67(0.65) \\
0.00-1.00\end{array}$ & 0.009 \\
\hline $\begin{array}{l}\text { MI after ER } \\
(\%)\end{array}$ & $\begin{array}{l}0.10(0.14) \\
0.00-1.00\end{array}$ & $\begin{array}{l}0.10(0.13) \\
0.00-0.64\end{array}$ & $\begin{array}{l}0.13(0.16) \\
0.00-1.00\end{array}$ & $>0.05$ \\
\hline $\begin{array}{l}\text { GV after ER } \\
(\%)\end{array}$ & $\begin{array}{l}0.12(0.16) \\
0.00-1.00\end{array}$ & $\begin{array}{l}0.15(0.11) \\
0.00-0.67\end{array}$ & $\begin{array}{l}0.13(0.16) \\
0.00-1.00\end{array}$ & $>0.05$ \\
\hline $\begin{array}{l}\text { MII at ICSI } \\
(\%)\end{array}$ & $\begin{array}{l}0.7(0.67) \\
0.00-1.00\end{array}$ & $\begin{array}{l}0.73(0.70) \\
0.00-1.00\end{array}$ & $\begin{array}{l}0.67(0.65) \\
0.00-1.00\end{array}$ & 0.013 \\
\hline $\begin{array}{l}\text { MII* at ICSI } \\
(\%)\end{array}$ & $\begin{array}{l}0.05(0.10) \\
0.00-1.00\end{array}$ & $\begin{array}{l}0.05(0.09) \\
0.00-0.55\end{array}$ & $\begin{array}{l}0.05(0.11) \\
0.00-1.00\end{array}$ & $>0.05$ \\
\hline $\begin{array}{l}\text { GV at ICSI } \\
(\%)\end{array}$ & $\begin{array}{l}0.11(0.15) \\
0.00-1.00\end{array}$ & $\begin{array}{l}0.11(0.15) \\
0.00-0.67\end{array}$ & $\begin{array}{l}0.13(0.16) \\
0.00-1.00\end{array}$ & $>0.05$ \\
\hline $\begin{array}{l}\text { Fertilized oocytes } \\
\text { (n) }\end{array}$ & $\begin{array}{l}8.00(10.20) \\
1.00-47.00\end{array}$ & $\begin{array}{l}10.00(12.07) \\
1.00-44.00\end{array}$ & $\begin{array}{l}6.00(8.68) \\
1.00-47.00\end{array}$ & $<0.001$ \\
\hline $\begin{array}{l}2 \mathrm{PN} \\
(\%)\end{array}$ & $\begin{array}{l}0.75(0.74) \\
0.00-1.00\end{array}$ & $\begin{array}{l}0.80(0.77) \\
0.17-1.00\end{array}$ & $\begin{array}{l}0.73(0.71) \\
0.00-1.00\end{array}$ & 0.006 \\
\hline $\begin{array}{l}\text { NEF } 2 \mathrm{~PB} \\
(\%)\end{array}$ & $\begin{array}{l}0.00(0.02) \\
0.00-1.00\end{array}$ & $\begin{array}{l}0.00(0.01) \\
0.0-0.33\end{array}$ & $\begin{array}{l}0.00(0.31) \\
0.0-1.00\end{array}$ & 0.021 \\
\hline $\begin{array}{l}\text { Non2PN } \\
(\%)\end{array}$ & $\begin{array}{l}0.06(0.11) \\
0.00-1.00\end{array}$ & $\begin{array}{l}0.06(0.10) \\
0.00-0.83\end{array}$ & $\begin{array}{l}0.06(0.13) \\
0.00-1.00\end{array}$ & $>0.05$ \\
\hline $\begin{array}{l}\text { Clvd on day } 3 \\
(\%)\end{array}$ & $\begin{array}{l}0.75(0.75) \\
0.00-1.00\end{array}$ & $\begin{array}{l}0.80(0.77) \\
0.00-1.00\end{array}$ & $\begin{array}{l}0.75(0.73) \\
0.13-1.00\end{array}$ & 0.031 \\
\hline$\underset{(\%)}{\geq 7}$ cell on day 3 & $\begin{array}{l}0.44(0.46) \\
0.00-1.00\end{array}$ & $\begin{array}{l}0.50(0.50) \\
0.00-1.00\end{array}$ & $\begin{array}{l}0.40(0.42) \\
0.00-1.00\end{array}$ & $<0.001$ \\
\hline $\begin{array}{l}\text { Blasts on day } 5 \\
(\%)\end{array}$ & $\begin{array}{l}0.00(0.11) \\
0.00-1.00\end{array}$ & $\begin{array}{l}0.07(0.17) \\
0.00-1.00\end{array}$ & $\begin{array}{l}0.00(0.07) \\
0.00-0.86\end{array}$ & $<0.001$ \\
\hline $\begin{array}{l}\text { Blasts on day } 6 \\
(\%)\end{array}$ & $\begin{array}{l}0.00(0.11) \\
0.00-0.84\end{array}$ & $\begin{array}{l}0.11(0.16) \\
0.00-0.84\end{array}$ & $\begin{array}{l}0.00(0.07) \\
0.00-0.60\end{array}$ & $<0.001$ \\
\hline $\begin{array}{l}\text { Embryo Transfer } \\
(\mathrm{ET})(\mathrm{n})\end{array}$ & $\begin{array}{l}3.00(2.86) \\
1.00-8.00\end{array}$ & $\begin{array}{l}3.00(2.92) \\
1.00-6.00\end{array}$ & $\begin{array}{l}3.00(2.81) \\
1.00-8.00\end{array}$ & $>0.05$ \\
\hline
\end{tabular}


established by using the forward stepwise discriminant analysis. Coefficient factors for the mentioned variables, discriminant function, and the two classificatory functions are presented in Table 2. Standardized coefficient factors showed that the number of transferred embryos $(\beta=0.42)$ and the number blastocysts on day $5(\beta=0.41)$ have the most positive influence on results of function and female age $(\beta=-0.70)$ has the most negative influence. This means that the older the female, the lower the value of the discriminant function and the higher the number of embryos transferred or number of blastocysts on day 5 , the higher the value of the function.

Table 2. Coefficient factors of the model (training set)

\begin{tabular}{|l|c|c|c|c|}
\hline \multirow{2}{*}{ Variables } & \multicolumn{2}{|c|}{ Discriminant function } & \multicolumn{2}{c|}{ Classificatory function } \\
\cline { 2 - 5 } & $\begin{array}{c}\text { Raw } \\
\text { coefficient } \\
\text { factors }\end{array}$ & $\begin{array}{c}\text { Standardized } \\
\text { coefficient } \\
\text { factors }\end{array}$ & Classifier 1 & Classifier 2 \\
\hline Blasts on day 5 (\%) & 2.30 & 0.41 & 18.69 & 20.53 \\
$\geq 7$ cell on day 3 (\%) & 1.21 & 0.30 & 1.94 & 2.90 \\
Embryo Transfer (n) & 0.36 & 0.42 & -0.07 & 0.22 \\
Female age (years) & -0.15 & -0.70 & 1.96 & 1.84 \\
NEF 2PB (\%) & -2.76 & -0.25 & 11.01 & 8.81 \\
Intercept & 3.75 & - & -39.49 & -36.72 \\
\hline
\end{tabular}

The median of the discriminant function for the training group with pregnancy was 0.39 and -0.46 for lack of pregnancy (Figure 1). There were significant differences $(p<0.001)$ between the groups. It is clear that a higher value of the discriminant function characterizes the pregnant group.

Table 3 presents the matrix for the correctly classified variables within the training group and within the validation group. The percentage of correctly classified pregnancies within the training group was $53.45 \%$, but within the validation group, this percentage was a little bit lower $-51.22 \%$. The percentages of cases in which there was a lack of pregnancy that were correctly classified were $75.62 \%$ and $74.07 \%$ respectively. The total percentage of correctly classified cases in the training set was $65.63 \%$; in the validation set, it was $64.21 \%$.

To assess the usefulness of prediction for the discriminant function, the value for each event of the validation group was created for the subsequent ROC curve analysis (Figure 2). The area under the curve was 0.73 and sensitivity was 0.512 , with a cut-off point of 0.277 . 
Anna Justyna Milewska et al.

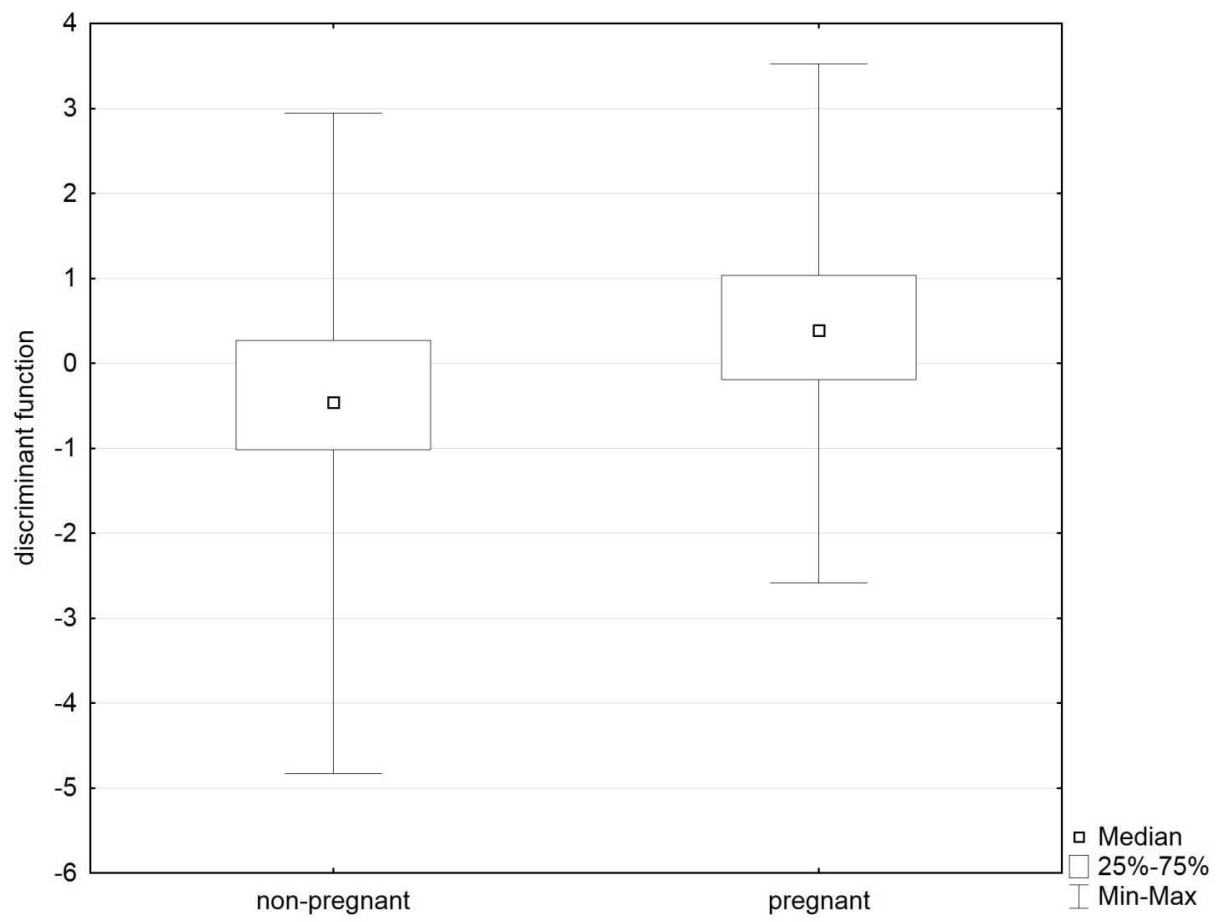

Figure 1. Values of the discriminant function for the groups with pregnancy and without pregnancy

Table 3. Matrix of correct classifications (training set, validation set)

\begin{tabular}{|l|l|l|l|l|c|}
\hline \multirow{2}{*}{ clinical outcome } & & & \multicolumn{2}{|c|}{ Probability of classification } & \multirow{2}{*}{ Total } \\
\cline { 4 - 5 } & & & Non-pregnant & Pregnant & \\
\hline \multirow{2}{*}{ training } & $\begin{array}{l}\mathrm{n} \\
(\%)\end{array}$ & Non-pregnant & $\begin{array}{l}214 \\
(75.62 \%)\end{array}$ & $\begin{array}{l}69 \\
(24.38 \%)\end{array}$ & 283 \\
\cline { 2 - 5 } & $\begin{array}{l}\mathrm{n} \\
(\%)\end{array}$ & Pregnant & $\begin{array}{l}108 \\
(46.55 \%)\end{array}$ & $\begin{array}{l}124 \\
(53.45 \%)\end{array}$ & 232 \\
\hline \multirow{2}{*}{ validation } & $\mathrm{n}$ & Non-pregnant & $\begin{array}{l}40 \\
(74.07 \%)\end{array}$ & $\begin{array}{l}14 \\
(25.93 \%)\end{array}$ & 54 \\
\cline { 2 - 5 } & $\mathrm{n}$ & Pregnant & $\begin{array}{l}20 \\
(48.78 \%)\end{array}$ & $\begin{array}{l}21 \\
(51.22 \%)\end{array}$ & 41 \\
\hline
\end{tabular}


Significance of Discriminant Analysis in Prediction of Pregnancy...

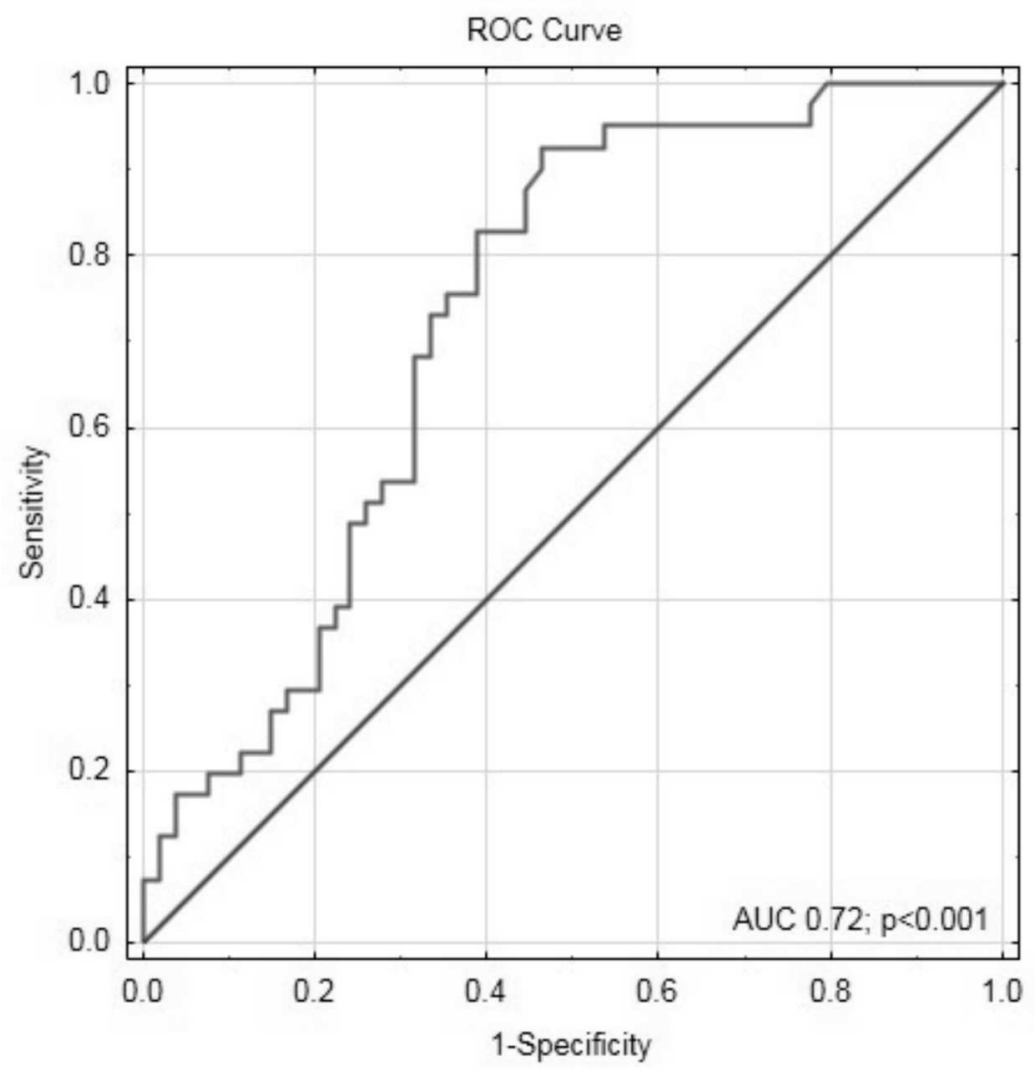

Figure 2. ROC curve (validation set)

\section{Conclusions}

The use of discriminant analysis made it possible to establish a model with only a $51 \%$ power of correctly predicting pregnancy in IVF treatment. Young female age, low percentage of abnormally developing embryos (NEF 2PB), high percentage of embryos on day 3 with more than 7 cells, high percentage of embryos developed to blastocyst stage on day 5 , and number of transferred embryos had a positive effect on becoming pregnant. However, the overall percentage of correct classification was more than $10 \%$ higher and was $64 \%$. A better prognostic quality was observed in prediction of failed pregnancies (74\%). Discriminant analysis is a method that allows one to determine cases with the lowest probability of success and it gives one the possibility to adjust the treatment; for example, the number of transferred embryos can be increased in order to improve the success of 
the treatment. Therefore, the created model is more practical in prediction of negative outcomes of IVF treatment, namely lack of pregnancy.

\section{R E F E R E N C E S}

Alunni, V., du Jardin, P., Nogueira, L., Buchet, L., \& Quatrehomme, G. (2015). Comparing discriminant analysis and neural network for the determination of sex using femur head measurements. Forensic Science International, 253, 81-87. DOI:10.1016/j.forsciint.2015.05.023

De Clercq, E. M., Leta, S., Estrada-Peña, A., Madder, M., Adehan, S., \& Vanwambeke, S. O. (2015). Species distribution modelling for Rhipicephalus microplus (Acari: Ixodidae) in Benin, West Africa: Comparing datasets and modelling algorithms. Preventive Veterinary Medicine, 118(1), 8-21. DOI:10.1016/j.prevetmed.2014.10.015

De Leon, T. B., Linscombe, S., Gregorio, G., \& Subudhi, P. K. (2015). Genetic variation in Southern USA rice genotypes for seedling salinity tolerance. Frontiers in Plant Science, 6:374. DOI:10.3389/fpls.2015.00374

Dobosz, M. (2001). Wspomagana komputerowo statystyczna analiza wyników badań. Warszawa: Akademicka Oficyna Wydawnicza EXIT.

Fanos, V., Noto, A., Xanthos, T., Lussu, M., Murgia, F., Barberini, L., Finco, G., et al. (2014). Metabolomics Network Characterization of Resuscitation after Normocapnic Hypoxia in a Newborn Piglet Model Supports the Hypothesis That Room Air Is Better. BioMed Research International, 2014, 731620. DOI: $10.1155 / 2014 / 731620$

Gajjar, K., Ahmadzai, A. A., Valasoulis, G., Trevisan, J., Founta, C., Nasioutziki, M., Loufopoulos, A., et al. (2014). Histology Verification Demonstrates That Biospectroscopy Analysis of Cervical Cytology Identifies Underlying Disease More Accurately than Conventional Screening: Removing the Confounder of Discordance. PLoS ONE, 9(1). DOI:10.1371/journal.pone.008 2416

Gnoth, C., Schuring, A. N., Friol, K., Tigges, J., Mallmann, P., \& Godehardt, E. (2008). Relevance of anti-Mullerian hormone measurement in a routine IVF program. Human Reproduction, 23(6), 1359-1365. DOI:10.1093/humrep/ $\operatorname{den} 108$

Huang, Z. L., Chen, X. P., Zhao, Q.Y., Zheng, Y. B., Peng, L., Gao, Z. L., \& Zhao, Z. X. (2015). An albumin, collagen IV, and longitudinal diameter of spleen scoring system superior to APRI for assessing liver fibrosis in chronic hepatitis B patients. International Journal of Infectious Diseases, 31, 18-22. DOI:10.1016/j.ijid.2014.10.030

Kim, S. C., Kim, M. K., Kim, Y. H., Ahn, S. A., Kim, K. H., Kim, K., Kim, W. K., et al. (2014). Differential levels of L-homocysteic acid and lysophosphatidylcholine (16:0) in sera of patients with ovarian cancer. Oncology Letters, 8(2), 566-574. DOI:10.3892/ol.2014.2214 
Lee, U. Y., Kim, I. B., \& Kwak, D. S. (2015). Sex determination using discriminant analysis of upper and lower extremity bones: New approach using the volume and surface area of digital model. Forensic Science International, 253, 135e1135e4. DOI:10.1016/j.forsciint.2015.05.017

Maeda, N., Urabe, Y., Murakami, M., Itotani, K., \& Kato, J. (2015). Discriminant analysis for predictor of falls in stroke patients by using the Berg Balance Scale. Singapore Medical Journal, 56(5), 280-283. DOI:10.11622/smedj.2015 033

Milewska, A. J., Górska, U., Jankowska, D., Milewski, R., \& Wołczyński, S. (2011). The use of the basket analysis in a research of the process of hospitalization in the gynecological ward. Studies in Logic, Grammar and Rhetoric. Logical, Statistical and Computer Methods in Medicine, 25(38), 83-98.

Milewska, A. J., Jankowska, D., Citko, D., Więsak, T., Acacio, B., \& Milewski, R. (2014). The use of principal component analysis and logistic regression in prediction of infertility treatment outcome. Studies in Logic, Grammar and Rhetoric. Logical, Statistical and Computer Methods in Medicine, 39(52), $7-23$.

Milewska, A. J., Jankowska, D., Cwalina, U., Więsak, T., Morgan, A., \& Milewski, R. (2013). Analyzing outcome of intrauterine insemination treatment by application of Cluster Analysis or Kohonen Neural Networks. Studies in Logic, Grammar and Rhetoric. Logical, Statistical and Computer Methods in Medicine, 35(48), 7-25.

Milewska, A. J., Jankowska, D., Górska, U., Milewski, R., \& Wołczyński, S. (2012). Graphical representation of the relationships between qualitative variables concerning the process of hospitalization in the gynecological ward using correspondence analysis. Studies in Logic, Grammar and Rhetoric. Logical, Statistical and Computer Methods in Medicine, 29(42), 7-25.

Milewski, R., Jamiołkowski, J., Milewska, A. J., Domitrz, J., Szamatowicz, J., \& Wołczyński, S. (2009). Prognosis of the IVF ICSI/ET procedure efficiency with the use of artificial neural networks among patients of the Department of Reproduction and Gynecological Endocrinology. Ginekologia Polska, 80(12), 900-906.

Milewski, R., Malinowski, P., Milewska, A. J., Czerniecki, J., Ziniewicz, P., \& Wołczyński, S. (2011). Nearest neighbor concept in the study of IVF ICSI/ET treatment effectiveness. Studies in Logic, Grammar and Rhetoric. Logical, Statistical and Computer Methods in Medicine, 25(38), 49-57.

Milewski, R., Milewska, A. J., Czerniecki, J., Leśniewska, M., \& Wołczyński, S. (2013a). Analysis of the demographic profile of patients treated for infertility using assisted reproductive techniques in 2005-2010. Ginekologia Polska, 84(7), 609-614.

Milewski, R., Milewska, A. J., Więsak, T., \& Morgan, A. (2013b). Comparison of artificial neural networks and logistic regression analysis in pregnancy prediction using in the in vitro fertilization treatment Networks. Studies in 
Logic, Grammar and Rhetoric. Logical, Statistical and Computer Methods in Medicine, 35(48), 39-48.

Pappas, A., Chaiworapongsa, T., Romero, R., Korzeniewski, S. J., Cortez, J. C., Bhatti, G., Gomez-Lopez, N. et al. (2015). Transcriptomics of Maternal and Fetal Membranes Can Discriminate between Gestational-Age Matched Preterm Neonates with and without Cognitive Impairment Diagnosed at 18 24 Months. PLoS ONE, 10(3). DOI:10.1371/journal.pone.0118573

Pires, L., Nogueira, M. S., Pratavieira, S., Moriyama, L. T., \& Kurachi, C. (2014). Time-resolved fluorescence lifetime for cutaneous melanoma detection. Biomedical Optics Express, 5(9), 3080-3089. DOI:10.1364/BOE.5.00 3080

Prentice, P., Koulman, A., Matthews, L., Acerini, C. L., Ong, K. K., \& Dunger, D. B. (2015). Lipidomic Analyses, Breast- and Formula-Feeding, and Growth in Infants. The Journal of Pediatrics, 166, 276-281.

Radwan, J., \& Wołczyński, S. (Eds.). (2011). Niepłodność i rozród wspomagany. Poznań, Polska: Termedia Wydawnictwa Medyczne.

Singh, N., Malik, E., Banerjee, A., Chosdol, K., Sreenivas, V., \& Mittal, S. (2013). Anti-Mullerian Hormone: Marker for Ovarian Response in Controlled Ovarian Stimulation for IVF Patients": A First Pilot Study in the Indian Population. The Journal of Obstetrics and Gynecology of India, 63(4), 268-272. DOI:10.1007/s13224-012-0318-6

Stanisz, A. (2007). Przystępny kurs statystyki z zastosowaniem STATISTICA PL na przykladach z medycyny, Tom 3. Analizy wielowymiarowe. Kraków, Polska: StatSoft.

Veeck, L. L. (1998). An atlas of human gametes and conceptuses. New York: Parthenon Publishing Group.

Vilke, A., Bilskiene, D., Šaferis, V., Gedminas, M., Bieliauskaite, D., Tamašauskas, A., \& Macas, A. (2014). Predictive value of early near-infrared spectroscopy monitoring of patients with traumatic brain injury. Medicina, 50(5), 263-268. DOI:10.1016/j.medici.2014.10.001

Wegdam, W., Moerland, P. D., Meijer, D., de Jong, S. M., Hoefsloot, H. C. J., Kenter, G. G., Buist, M. R., et al. (2012). A critical assessment of SELDITOF-MS for biomarker discovery in serum and tissue of patients with an ovarian mass. Proteome Science, 10:45.

Xia, L., Zhao, X., Sun, Y., Hong, Y., Gao, Y., \& Hu, S. (2014). Metabolomic profiling of human follicular fluid from patients with repeated failure of in vitro fertilization using gas chromatography/mass spectrometry. International Journal of Clinical and Experimental Pathology, 7(10), 7220-7229.

Zhao, J., Zhang, Q., Wang, Y., \& Li, Y. (2014). Endometrial pattern, thickness and growth in predicting pregnancy outcome following 3319 IVF cycle. Reproductive BioMedicine Online, 29(3), 291-298. DOI:10.1016/j.rbmo.2014.05.011 